\title{
THEMATIC PAPER \\ Mind games: standing by while the world ignores climate change
}

\author{
Daniel L. Maughan ${ }^{1}$ and Helen L. Berry ${ }^{2}$
}

'Sustainability Fellow, Royal College of Psychiatrists, London, UK; Centre for Sustainable Healthcare, Oxford, UK, email daniel.maughan sustainablehealthcare.or.tk sustainablehealthcare.org. Climate Change Institute, The Australian National University: Australan National Univ University of Canberra, Australia
The mental health effects of climate change are significant and highly concerning, yet little is known about the magnitude of these effects or how best to manage them. This introduction to the thematic papers in this issue explains why climate change is an increasingly important matter for all health services.

The United Nations (UN) has a track record of identifying the global issues that define each generation. The Millennium Development Goals, the most recent programme, achieved good success (UN, 2013), perhaps partly because they included easy-to-understand health goals such as 'improve maternal health' and 'reduce child mortality' (UN, 2013). Framing goals to address the increasingly complex problems that will face us through to the middle of the 21st century, especially climate change and its impact on health, may not be so simple. The UN's Sustainable Development Goals currently in preparation will dominate the post-2015 UN development agenda (Sachs, 2012). Perhaps unsurprisingly, given continued population growth and the increasing prevalence of consumption-oriented ways of living, these goals focus on ecosystems, natural resources, water and agricultural practices. Importantly, a new goal has been added: 'Take urgent action to combat climate change and its impacts' (UN, 2014).

While this is self-evidently important (Intergovernmental Panel on Climate Change, 2013), the UN's lack of specific focus on human health impacts is a significant concern: to be blunt, if we care about climate change, it is because we care about human well-being (Mcmichael et al, 2014). The earth would endure without our species; indeed, we could argue that the sooner we warm our planet sufficiently to render ourselves few or extinct, the sooner our planet's ecosystems will be able to begin restoring themselves. But if we start acting in the interests of human well-being for the next century instead of just the next week, we will, de facto, do the things needed to take care of the earth's life-support system and the world's most vulnerable people and places. Have no doubt: this is our mess and we have to fix it now.

\section{Climate change and health}

It is now unlikely that global warming will remain within the $2^{\circ} \mathrm{C}$ 'guardrail' increase from preindustrial global temperature levels; the effects this is likely to have on human health are predicted to be catastrophic (Intergovernmental Panel on Climate Change, 2014). More and more leading voices, such as the World Health Organization (WHO) and the Lancet, have proclaimed climate change to be the largest threat to human health in the 21st century (Chan, 2008; Costello et al, 2009). In 2015, the Lancet will launch a second commission to examine this issue further, particularly the sustainability of human civilisations in the face of multiple environmental threats (Lancet, 2014).

As always, mental health is the Cinderella of health, mentioned only in passing, if at all. Yet by 2010, largely due to population growth and ageing, mental and substance use disorders were already the world's leading cause of years lived with disability (Whiteford et al, 2013). Climate change could profoundly harm mental health (Berry et $a l, 2010)$ and, because mental illness is associated with substantial disability, it will mean an increased challenge to patients' adaptive capacity and coping that psychiatry cannot overlook. If nothing else, those with mental disorders and their service providers and carers will have to be prepared to cope with the immediate crisis and the later aftermath of increasingly severe and frequent extreme weather events. We can look forward to more and worse drought, cyclones, flooding and heatwaves, all of which have detrimental effects on mental health (Page et al, 2007; Hayes et al, 2009; Murray et al, 2011; McDermott et al, 2014; OBrien et al, 2014) and many of which may co-occur (e.g. drought and extreme heat).

Leading international institutions such as the $\mathrm{UN}$ and the WHO are taking climate change seriously. But most national health services remain unresponsive to this threat to human health and, indeed, to their own contribution to the problem, despite calls to action (Pencheon, 2009; Blashki et al, 2011; Costello et al, 2013). For example, in the UK, the healthcare sector emits 25 million tonnes of carbon per year and is the largest emitter of greenhouse gases in the public sector (NHS Sustainable Development Unit, 2013). Most other countries have not measured the carbon footprint of their healthcare systems. Similarly, medical training institutions and primary care settings have done little to include climate change in professional and service development, again despite calls for such action and suggestions for how to go about it (Blashki et al, 2009; Green et al, 2009; Maughan et al, 2014).

\section{A service response}

Why is it that doctors, whose aim it is to improve health (and, above all, to do no harm) are, with the emissions associated with delivering healthcare, adding significantly to the health threat posed 
by climate change? One reason could be that climate change is too complex a phenomenon with which to engage, a circumstance which, combined with the complexity of mental health, has led to paralysis. If the largest threat to human health this century were a disease, perhaps psychiatrists would know about it and perhaps more research would be implemented aimed at how to tackle the problem - as has been the case for the impacts of climate change on the spread of infectious and vector-borne diseases. However, the mental health effects of climate change provide no classic pathological process for psychiatrists to engage with or understand; and climate change will have effects primarily at the community rather than at the individual level. Furthermore, the mental health effects of climate change are wide-ranging and grossly entwined with the social, geographical and political context (Berry et al, 2010; OBrien et al, 2014). Greater understanding is needed of how climate change will affect communities and what communities can do to prepare and respond, especially as key actions would be beneficial to resilience and adaptive capacity, that is, to collective and individual mental health and well-being.

We are far from having a good understanding of these multifaceted effects. However, professionals in mental health have skills that are of particular pertinence in managing the effects of climate change. Understanding how individuals might adapt to climate change and the psychological responses (anxiety) and interpersonal behavioural processes (seeking social support or helping others) that may arise require a knowledge of psychology. Psychiatrists, psychologists and mental health research leaders could help individuals and whole communities consider how best to adapt to the effects climate change will have on local ecosystems and infrastructures. Herein lies a jewel as yet unpolished: the act of coming together under effective local leadership to solve collective local problems, acting for the greater good, can build social capital, which is powerfully protective of mental health (Berry, 2009).

What is clear is that doctors should be advocates for climate change mitigation and adaption, including in the workplace. We can begin this process first by gaining more understanding about how climate change might affect both population and individual mental health, and second by reducing the carbon footprint of healthcare. We must also inform, promote and support community-level activities to mitigate or adapt.

The three thematic articles in this issue on climate change discuss the necessary responses. The first explores how population-level attitudes to climate change are linked to mental health and well-being, and how these linkages are moderated by demographic and socioeconomic characteristics in rural and remote Australia. The second records emerging evidence for local adaptation among women in Nepal. The third provides an exploratory analysis of how a mental health organisation might reduce its carbon footprint. That last article focuses specifically on how reducing the internationally ubiquitous phenomenon of clinic non-attendance can lead to improved quality of care while reducing environmental and economic costs.

\section{References}

Berry, H. L. (2009) Pearl in the oyster: climate change as a mental health opportunity. Australasian Psychiatry, 17, 453-456.

Berry, H. L., Bowen, K. \& Kjellstrom, T. (2010) Climate change and mental health: a causal pathways framework. International Journal of Public Health, 55, 123-132.

Blashki, G., Berry, H. L. \& Kidd, M. R. (2009) Primary health care responses to climate change. In Climate Change and Social Justice (ed. J. Moss), pp. 144-167. Melbourne University Press.

Blashki, G., Armstrong, G., Berry, H. L., et al (2011) Preparing health services for climate change in Australia. Asia-Pacific Journal of Public Health, 23 (Suppl. 2), 133S-143S

Chan, M. (2008) The Impact of Climate Change on Human Health. WHO

Costello, A., Abbas, M., Allen, A., et al (2009) Managing the health effects of climate change. Lancet, 373, 1693-1733.

Costello, A., Montgomery, H. \& Watts, N. (2013) Climate change: the challenge for healthcare professionals. BMJ (Clinical Research), $347, f 6060$.

Green, E. I. H., Blashki, G., Berry, H. L., et al (2009) Preparing Australian medical students for climate change. Australian Family Physician, 38, 726-729

Hayes, J., Mason, J., Brown, F., et al (2009) Floods in 2007 and older adult services: lessons learnt. Psychiatric Bulletin, 33, 332-336. Intergovernmental Panel on Climate Change (2013) Climate Change 2013. United Nations. Available at http://www. climatechange2013.org/images/uploads/WGI_AR5_SPM_brochure. pdf (accessed 26 October 2013).

Intergovernmental Panel on Climate Change (2014) Climate Change 2014: Impacts, Adaptation, and Vulnerability. Part A: Global and Sectoral Aspects. Contribution of Working Group II to the Fifth Assessment Report of the Intergovernmental Panel on Climate Change. Cambridge University Press.

Lancet (2014) Climate change and health - action please, not words. Lancet, 384, 1071

Maughan, D., Berry, H. \& Davison, P. (2014) What psychiatrists should know about environmental sustainability and what they should be doing about it. International Psychiatry, 11, 27-30.

McDermott, B., Cobham, V., Berry, H., et al (2014) Correlates of persisting posttraumatic symptoms in children and adolescents 18 months after a cyclone disaster. Australian and New Zealand Journal of Psychiatry, 48, 80-86.

McMichael, A. J., Berry, H. L. \& Butler, C. (2014) Climate change. IPCC Impacts report: staring into the abyss. World Nutrition, 5 , 432-435.

Murray, V., Caldin, H., Amlot, R., et al (2011) The Effects of Flooding on Mental Health. Health Protection Agency.

NHS Sustainable Development Unit (2013) Goods and Services Carbon Hotspots. Available at http://www.sdu.nhs.uk/documents/ resources/Hotspot_full.pdf (accessed 12 March 2015).

OBrien, L. V., Berry, H. L., Coleman, C., et al (2014) Drought as a mental health exposure. Environmental Research, 131, 181-187.

Page, L. A., Hajat, S. \& Kovats, R. S. (2007) Relationship between daily suicide counts and temperature in England and Wales. British Journal of Psychiatry, 191, 106-112.

Pencheon, D. (2009) Health services and climate change: what can be done? Journal of Health Services Research and Policy, 14, 2-4.

Sachs, J. D. (2012) From Millennium Development Goals to Sustainable Development Goals. Lancet, 379, 2206-2211.

UN (2013) The Millennium Development Goals Report. United Nations.

UN (2014) Outcome Document - Open Working Group on Sustainable Development Goals. Available at http://sustainable development.un.org/focussdgs.html (accessed 8 October 2014)

Whiteford, H. A., Degenhardt, L., Rehm, J., et al (2013) Global burden of disease attributable to mental and substance use disorders: findings from the Global Burden of Disease Study 2010. Lancet, 382, 1575-1586. 